\title{
PENGARUH PERMAINAN TERHADAP KEMAMPUAN PASSING BAWAH BOLAVOLI PADA PESERTA DIDIK KELAS VIII MTSN 6 JOMBANG
}

\author{
Arnaz Anggoro Saputro \\ Pendidikan Jasmani, STKIP PGRI Jombang \\ email: arnaz.anggoro@stkipjb.ac.id
}

\begin{tabular}{l}
\hline Artikel Info \\
\hline Koresponden penulis: \\
Arnaz Anggoro Saputro \\
Email: arnaz.anggoro@stkipjb.ac.id \\
\\
$\square$ Diterima 1 Oktober 2020 \\
$\square$ Direview 30 Oktober 2020 \\
$\square$ Disetujui 31 Oktober 2020 \\
$\square$ Dipublikasi 31 Oktober 2020
\end{tabular}

Kata Kunci:

Permainan, passing bawah bolavoli

Keywords:

Game, under passing the volleyball

\begin{abstract}
Abstrak
Tujuan Penelitian ini adalah untuk mengetahui ada tidaknya Pengaruh Permainan Terhadap Kemampuan Passing Bawah Bolavoli pada Peserta Didik Kelas VIII-B MTsN 6 Jombang. Jenis penelitian kuantitatifmenggunakan model One group Pretest- Posttest Design. Sampel seluruh peserta didik kelas VIII-B MTsN 6 Jombang. Penilaian tes ini yang dinilai yaitu kemampuan Passing Bawah. Berdasarkan hasil penelitian, bahwa pada hasil penelitian ini diperoleh perhitungan hasil proses pada tabel Paired Samples T-Test diperoleh Sig (2-tailed) sebesar 0,000. Hal ini berarti nilai sig 0,000 <0,05, maka $\mathrm{HO}_{0}$ ditolak. Berdasarkan data tersebut dapat disimpulkan bahwa ada pengaruh permainan terhadap kemampuan passing bawah pada peserta didik kelas VIIIB MTsN 6 Jombang. Sesuai dengan deskriftif data dan pembahasan, maka dapat disimpulkan bahwa terdapat pengaruh yang signifikan antara permainan terhadap kemampuan passing bawah pada peserta didik kelas VIII-B MTsN 6 Jombang. maka peneliti menyarankan sebagai berikut: (1) Dengan adanya penelitian ini diharapkan dapat menjadi salah satu acuan dalam pembelajaran PJOK khususnya passing bawah dalam pembelajaran bola voli agar lebih kreatif dan inovatif. (2) Untuk penyempurnaan hasil penelitian yang lebih baik maka perlu dilakukan penelitian lagi. (3) Untuk mendapatkan hasil yang lebih baik, perlu dilakukan penelitian dengan populasi yang lebih luas terhadap sampel yang diperketat.
\end{abstract}

\begin{abstract}
The purpose of this study was to determine whether there was an effect of the game on the under passing ability the volleyball on class VIII-B students of MTsN 6 Jombang. This type of quantitative research uses the One group Pretest-Posttest Design model. The sample of all students of class VIII-B MTsN 6 Jombang. Assessment of this test is assessed namely the ability of the Lower Passing. Based on the results of the study, that the results of this study obtained the calculation of the results of the process in the Paired Samples T-Test table obtained Sig (2-tailed) of 0,000. This means that the value of sig 0,000<0.05, then $\mathrm{HO}$ is rejected. Based on these data it can be concluded that there is an influence of the game on the ability to pass underneath the students of class VIII-B MTsN 6 Jombang. In accordance with the descriptive data and discussion, it can be concluded that there is a significant influence between the game on the under passing ability the students of class VIII-B MTsN 6 Jombang. The researcher suggests as follows: (1) With this research it is hoped that it can become one of the references in learning Physical Education, especially passing down in volleyball learning to be more creative and innovative. (2) For the improvement of better research results, further research is needed. (3) To get better results, it is necessary to do research with a wider population of tightened samples.
\end{abstract}




\begin{tabular}{|c|c|c|}
\hline Unipa Sumalaga & $\begin{array}{l}\text { Journal STAND: Sports and Development } \\
\text { http://jurnal.unipasby.ac.id/index.php/stand/about/submissions } \\
\text { jurnal.stand@unipasby.ac.id }\end{array}$ & 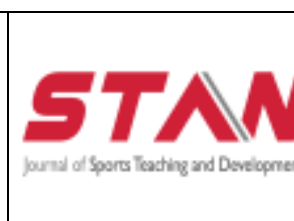 \\
\hline
\end{tabular}

\section{PENDAHULUAN}

Pendidikan jasmani dan olahraga dapat memberikan kesempatan pada peserta didik untuk terlibat langsung dalam aneka pengalaman belajar melalui aktivitas jasmani, bermain dan berolahraga yang dilakukan secara sistematis, terarah, dan terencana. Pembekalan pengalaman belajar itu diarahkan untuk membina, sekaligus membentuk gaya hidup sehat dan aktif sepanjang hayat. Pendidikan jasmani dan olahraga adalah usaha sadar untuk menimbulkan perubahan tingkah laku hidup sehat. Perubahan itu terutama pada diri seseorang, yang kemudian mempengaruhi lingkungan hidup masyarakat disekitarnya. Dengan demikian masalah kesehatan bukan hanya urusan per orang, tapi merupakan masalah sosial. (Lutan, 2012:75).

Pada saat pelaksanaan pembelajaran yang dilaksanakan pada guru PJOK selaku peneliti yang di MTsN 6 Jombang kelas VIII semester ganjil tahun ajaran 2019/2020. Berdasarkan silabus dengan materi1) menendang, mengiring, mengumpan, serta menyundul dalam permainan sepak bola, 2) bolavoli seperti: passing bawah, passing atas, servis bawah, servis atas, smash/spike, dan block/bendungan, 3)bola basket, seperti: melempar bola, menggiring bola, menangkap bola, menembak bola, dan merebound bola, 4)bola kasti, seperti: melempar bola, menangkap bola, dan memukul bola. Permainan passing bawah bolavoli merupakan keterampilan minimal agar permainan bolavoli dapat dilakukan, selain itu teknik ini merupakan dasar bagi pelaksanaan suatu serangan.Serangan dalam permainan bolavoli selalu diawali dengan passing.

Dalam perkembangannya permainan bolavoli membutuhkan passing yang akurat dan terampil agar didapat suatu kerja sama yang bagus untuk memenangkan suatu pertandingan. Menurut (Mutohir, 2013:64), keterampilan passing dapat dikembangkan dengan 3 cara, yaitu, pertama adalah passing secara perorangan khususnya passing bawah atau passing atas yang dapat dilakukan dengan cara memasing bola ketembok, ketinggian bola minimal dan maksimal yang ditandai dengan garis batas. Sedangkan cara passing yang kedua adalah dengan berpasangan. Passing bawah dan passing atas dapat dilakukan secara berpasangan, hal tersebut dilakukan dalam rangka mengembangkan keterampilan passing bola dengan baik. Pertama diawali dengan passing bawah dilakukan secara berpasangan, kedua pemain mengambil jarak yang sudah ditentukan agar dapat mempassing bola dan hasil passing dapat diterima oleh pasangannya, sehingga pasangannya juga mengembalikan dengan baik. Lakukan passing bawah dengan pasangan berulang - ulang sampai mampu mengontrol bola dengan baik. Yang ketiga adalah melakukan passing secara berkelompok yakni melakukan passing bawah empat sampai lima orang dalam lingkup 


\begin{tabular}{|c|c|}
\hline & Journal STAND: Sports and Development \\
umipa Sumalmya & http://jurnal.unipasby.ac.id/index.php/stand/about/submissions \\
jurnal.stand@unipasby.ac.id
\end{tabular}

lingkaran kecil sampai pada lingkaran ukuran sedang dan besar.

Selama ini guru hanya mengajar dengan menggunakan materi dan kurangnya variasi permainan pada saat menyampaikan teknik dasar bola voli terutama pada permainan passing bawah. Sehingga guru harusnya dituntut lebih kreatif dan inovatif dalam menerapkan materi proses pembelajaran yang disampaikan guru agar bisa diterima dan peserta didik pun senang dalam mengikuti pembelajaran bola voli. Dari pertanyaan yang pertama bahwa masalah dalam passing bawah permainan bolavoli yaitu kurang antusiasnya peserta didik dilapangan. Memang dalam penilaian terdapat 3 ranah yang tidak bisa terpisahkan, akan tetapi dengan adanya keterangan dengan guru mata pelajaran diatas bahwa peserta didik kurang antusias sehingga kemampuan yang dimiliki kurang bisa disalurkan dengan maksimal, maka dapat di ambil kesimpulan bahwa untuk permasalahan yang ada di kelas tersebut pada aspek kemampuan (psikomotor).

\section{METODE PENELITIAN}

Penelitian ini adalah penelitian eksperimen, penelitian eksperimen adalah penelitian yang dilakukan secara ketat untuk mengetahui hubungan sebab akibat diantara variabelvariabel. Salah satu ciri utama penelitian eksperimen adalah adanya perlakuan yang dikatakan pada subjek atau objek penelitian. Penelitian ini menggunakan jenis penelitian penelitian kuantitatif dengan metode Pre experiment design menggunakan model One Group Pretest-Posttest Design.

Populasi dalam penelitian ini adalah seluruh peserta didik yang ada di kelas VIII MTsN 6 Jombang yang terdiri dari 4 kelas yang jumlah keseluruhan peserta didik yaitu 111 peserta didik. Tehnik pengambilan sampel dari penelitian ini menggunkan tehnik simple random sampling. Instrument yang digunakan peneliti dalam penelitian ini adalah penilaian tes passing bawah permainan bolavoli. Dengan teknik analisis data menggunakan SPSS versi 20 rumus uji homogenitas, uji normalitas dan uji-t.

\section{HASIL DAN PEMBAHASAN}

Pada bagian ini akan dikemukakan pengujian hipotesis berdasarkan dari data pengaruh permainan terhadap hasil kemampuan passing bawah bolavoli pada peserta didik kelas VIII B MTsN 6 Jombang. Kemudian hasil data diolah dan dianalisis secara statistik untuk menguji hipotesis yang sudah diajukan sebelumnya. Adapun datadata yang didapatkan sebagai berikut:

\section{Uji Normalitas}

Langkah pertama yang dilakukan adalah dengan menguji data pretest dan posttest para peserta didik untuk mengetahu data yang sudah diperoleh berdistrubusi normal. Maka dilakukan uji normalitas menggunakan uji Kolmogorov Smirnov SPSS 20.

Volume 1 Nomor 2 Tahun 2020 | 91 


\begin{tabular}{|c|c|c|}
\hline Unipa Sunalanga & $\begin{array}{l}\text { Journal STAND: Sports and Development } \\
\text { http://jurnal.unipasby.ac.id/index.php/stand/about/submissions } \\
\text { jurnal.stand@unipasby.ac.id }\end{array}$ & 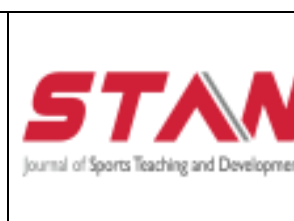 \\
\hline
\end{tabular}

Tabel 1. Uji Normalitas

\begin{tabular}{llrr}
\hline \multicolumn{3}{c}{ One-Sample Kolmogorov-Smirnov Test } \\
& & pretest & Posttest \\
\hline $\mathrm{N}$ & & 31 & 31 \\
& & 2.6452 & 4.8065 \\
Normal Parameters $\mathrm{a}, \mathrm{b}$ & Mean & 1.27928 & 1.64153 \\
& Std. & & \\
& Deviation & .209 & .227 \\
& Absolute & .209 & .227 \\
Most Extreme & Positive & -.178 & -.128 \\
Differences & Negative & 1.164 & 1.265 \\
Kolmogorov-Smirnov Z & & .133 & .081 \\
Asymp. Sig. (2-tailed) & & & \\
\hline
\end{tabular}

Bedasarkan hasil output SPSS di atas diperoleh nilai Asymp. Sig. (2-tailed) pada nilai pretest sebesar 0,133 sehingga $0,133>$ 0,05, maka H0 diterima jadi data berdistribusi normal. Sedangkan untuk nilai posttest sebesar 0,081 sehingga 0,081 >0,05 maka h0 diterima jadi data berdistribusi normal. Jadi dapat disimpulkan bahwa data nilai pretest dan posttest berdistribusi normal.

\section{Uji Homogenitas}

Setelah data penelitian berdistribusi normal, salanjutnya dilakukan pengujian homogenitas varian pada hasil data tes menggunakan SPSS 20

Tabel 2. Uji Homogenitas

\begin{tabular}{|c|c|c|c|}
\hline & & Levene Statistic & Sig. \\
\hline Nilai & Mean & .696 & .407 \\
\hline seluruh & Median & .476 & .493 \\
\hline
\end{tabular}

Berdasarkan output hasil SPSS di atas dengan $\alpha=0,05$, didapat nilai sig untuk Based on Mean sebesar 0,407. Hal ini berarti nilai sig
0,407 > 0,05, maka H0 diterima. Jadi dapat disimpulkan bahwa nilai pretest dan posttest bersifat homogen atau memiliki varian yang sama.

\section{Uji Hipotesis (Uji t)}

Tabel 3. Uji T

\begin{tabular}{lccccc}
\hline & & \multicolumn{4}{c}{ Std. } \\
& $\begin{array}{c}\text { Std. } \\
\text { Mean } \\
\text { Deviat } \\
\text { i on } \\
\text { pro } \\
\text { pretest }\end{array}$ & $\begin{array}{c}\text { Mea } \\
\mathrm{n}\end{array}$ & $\mathrm{t}$ & Sig \\
postest & -2.16129 & .73470 & .13196 & -16.379 & .000 \\
\hline
\end{tabular}

Berdasarkan output SPSS 20 di atas didapatkan hasil nilai Sig (2-tailed) sebesar 0,000. H0 diterima jika nilai Sig $>\alpha$ dan H0 ditolak jika nilai $\mathrm{Sig}<\alpha$. Hal ini berarti nilai sig $0,000<0,05$, maka H0 ditolak. Sehingga dapat disimpulkan bahwa ada pengaruh permainan terhadap kemampuan passing bawah pada peserta didik kelas VIII MTsN 6 Jombang.

Berdasarkan output SPSS 20 di atas didapatkan hasil nilai Sig (2-tailed) sebesar 0,000. H0 diterima jika nilai Sig $>\alpha$ dan H0 ditolak jika nilai $\mathrm{Sig}<\alpha$. Hal ini berarti nilai sig $0,000<0,05$, maka H0 ditolak. Sehingga dapat disimpulkan bahwa ada pengaruh permainan terhadap kemampuan passing bawah pada peserta didik kelas VIII MTsN 6.

Jombang. Hal ini dapat terjadi karena pembelajaran menggunakan permainan yang dapat menunjang kemampuan passing bawah bolavoli dan kesenangan para peserta didik dalam mengikuti pembelajaran passing bawah, 


\begin{tabular}{|c|c|c|}
\hline Unipa Sumalaga & $\begin{array}{l}\text { Journal STAND: Sports and Development } \\
\text { http://jurnal.unipasby.ac.id/index.php/stand/about/submissions } \\
\text { jurnal.stand@unipasby.ac.id }\end{array}$ & 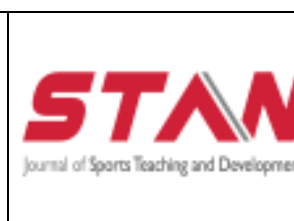 \\
\hline
\end{tabular}

sehingga materi dapat disampaikan dan diterima dengan baik oleh para peserta didik. Peneliti memberikan 7 kali pertemuan. Pada pertemuan pertama dilakukan pretest dan treatment, pada pertemuan kedua sampai pertemuan keenam dilakukan treatment dan pertemuan ketujuh dilakukan posttest.

\section{KESIMPULAN}

Sesuai dengan deskriftif data dan pembahasan, maka dapat disimpulkan bahwa terdapat pengaruh permainan terhadap kemampuan passing bawah pada peserta didik kelas VIII MTsN 6 Jombang. Sehingga dengan adanya penelitian ini diharapkan dapat menjadi salah satu acuan dalam pembelajaran PJOK khususnya passing bawah dalam pembelajaran bola voli agar lebih kreatif dan inovatif, untuk penyempurnaan hasil penelitian yang lebih baik maka perlu dilakukan penelitian lagi, untuk mendapatkan hasil yang lebih baik, perlu dilakukan penelitian dengan populasi yang lebih luas terhadap sampel yang diperketat

\section{REFERENSI}

Afandi, C. W. (2013). Model \& Metode Pembelajaran di Sekolah. Unissula Press.Semarang: Universitas Islam Sultan Agung Semarang.

Albertus, F. (2016). Tes \& Pengukuran dalam Olahraga. (M. Bendatu, Ed.). Yogyakarta: CV ANDI OFFSET.

Arikunto, S. (2010). Prosedur Penelitian. Jakarta: PT. RINEKA CIPTA, Jakarta.
Darmadi. (2017). Pengembangan Model \& Metode Pembelajaran (1st ed.). Yogyakarta: CV. BUDI UTAMA.

Dimyati. (2013). Belajar dan Pembelajaran. (Dr. Dimyati, Ed.). Jakarta: PT. RINEKA CIPTA, Jakarta.

Hartati. (2012). Permainan Kecil. Malang: Wineka Media.

Husamah. (2016). Belajar dan Pembelajaran. Malang: Universitas Muhammadiyah Malang.

Lutan, R. (1998). MANUSIA DAN OLAHRAGA. Bandung: ITB dan FPOK/IKIP Bandung.

Maksum, A. (2012). Metode Penelitian. Surabaya: UNESA University Press.

Maksum, A. (2015). Metodelogi Penelitian. Surabaya: Unesa University Press.

Mutohir, C. T. (2013). Permainan Bola Voli. (Mutaqim, Ed.). Surabaya: GRAHA PUSTAKA MEDIA UTAMA.

Nurhasan. (2000). Tes dan Pengukuran Pendidikan Olahraga, 1.

Sugiyono. (2016). Metode Penelitian

Kuantitaf Kualitatif dan R\&D.

Bandung. 